\title{
Agradecimiento al Profesor Emérito Javier María Iguíñiz Echeverría
}

\section{Dra. Graciela Tonon \\ Directora del Journal de Ciencias Sociales-UP}

Quisiera dedicar este número al Dr. Javier María Iguíñiz Echeverría, pionero de los estudios de desarrollo humano en América Latina.

Javier nació en la ciudad de Lesaca, Navarra, España pero en su adolescencia se trasladó con su familia a Perú y allí adoptó esa nacionalidad.

Completó sus estudios de bachillerato en Ingeniería Mecánica y Eléctrica en la Universidad Nacional de Ingeniería (PERU-1968). Posteriormente obtuvo un título de Master of Science en Economía por la lowa State University (EEUU-1972) y un título de Ph.D. en Economía por The New School for Social Research (EEUU-1979) con su tesis: Elements Towards a More General Theory of Unequal Exchange. Posteriormente, en 1998 se graduó de Ingeniero Electricista en la Universidad Nacional de Ingeniería.

A lo largo de su vida Javier obtuvo diversas becas: AID, EE.UU. 1970-1972; Fundación Ford, EE.UU. 1972-1973 y 1992; ACDI, Canadá, 1978-1979 y Fundación John S. Guggenheim EE.UU. 1994. Asimismo, fue galardonado con menciones tales como la de Profesor Honorario de la Universidad San Agustín de Arequipa (1993); Doctor Honoris Causa de la Universidad Nacional de Cajamarca, (1996); Miembro Honorario del Colegio de Economistas del Perú (1999) y Doctor Honoris Causa de la Universidad Nacional Hermilio Valdizán, Huanuco (2010).

Javier ha escrito, de manera precisa y amena, con un estilo propio y exquisito, una vasta colección de libros, capítulos de libros, artículos científicos y ensayos, referidos al desarrollo humano, la pobreza, la desigualdad, la democracia y también la religión.

En el campo de la política ha ocupado roles protagónicos en la historia social y política de su país, habiéndose desempeñado como Presidente del Consorcio de Investigación Económica y Social (CIES); como Director del Fondo Nacional de Compensación y Desarrollo Social (FONCODES), como Miembro del Consejo Nacional de Educación, del Consejo Consultivo del Ministerio de Trabajo y del Consejo de la Orden del Trabajo y como miembro de la Mesa de Concertación para la Lucha Contra la Pobreza. En 2011 fue nombrado Secretario Técnico del Acuerdo Nacional, foro que elabora y aprueba lineamientos en 
políticas del Estado en base al diálogo y concertación entre los tres niveles de gobierno y las instituciones políticas y sociales del Perú, ejerciendo el cargo hasta el año 2020.

En su carrera académica, se ha desempeñado como Profesor de Economía en la Pontificia Universidad Católica del Perú, casa de estudios de la cual es Profesor Emérito. Asimismo, fue fundador del Instituto de Desarrollo Humano para América Latina (IDHAL) del cual es su Presidente.

Ha sido Profesor Visitante en la Universidad de Notre Dame y en la Universidad de Oxford, así como investigador visitante del Instituto Tecnológico de Massachusetts (MIT).

Es para mí un honor poder escribir estas líneas, y de esta manera agradecer a Javier por el trabajo y dedicación de toda su vida. Tuve la dicha de conocerlo en México hace ya 14 años, en oportunidad de que conjuntamente con otros colegas de la región, fundáramos ALCADECA, la Asociación Latinoamericana y del Caribe para el estudio de las Capacidades Humanas. Desde ese momento siempre hemos mantenido un vínculo de amistad y de colaboración en distintos proyectos y publicaciones dedicados al desarrollo humano de nuestra región.

Javier es para mí, un maestro de quien he aprendido mucho, pero fundamentalmente un íntegro ser humano y un defensor del respeto a los derechos humanos y a las libertades de las personas, muchas gracias Javier por todo lo que nos has enseñado y por todo lo que nos seguirás enseñando. 